\title{
FREQUENCY ANALYSIS OF MODIS NDVI TIME SERIES FOR DETERMINING HOTSPOT OF LAND DEGRADATION IN MONGOLIA
}

\author{
Elbegjargal Nasanbat ${ }^{1 *, 3},{ }^{*}$ Sainzaya Sharav ${ }^{2}$, Tuya Sanjaa², Ochirkhuyag Lkhamjav ${ }^{3}$, \\ Erdenetuya Magsar ${ }^{3,4}$, Battsetseg Tuvdendorj ${ }^{5}$
}

\author{
${ }^{1}$ Information and Research Institute of Meteorology, Hydrology and Environment; Juulchiny street-5, \\ Ulaanbaatar 15160, Mongolia; n.elbegjargal@ gmail.com \\ ${ }^{2}$ School of Applied Sciences, Mongolian University of Science and Technology; \\ sharavsainzaya1@gmail.com, s_tuya20@yahoo.com \\ ${ }^{3}$ Mongolian Geospatial Association, P.O. Box 24/38, Ulaanbaatar 15141, Mongolia; \\ mongeoinfo@gmail.com,ochirkhuyag@geomedeelel.mn \\ ${ }^{4}$ National Agency for Meteorology and Environmental Monitoring, Juulchiny street-5, \\ Ulaanbaatar 15160, Mongolia; m_erdenetuya@yahoo.com
}

${ }^{5}$ Key Laboratory of Digital Earth Science, Institute of Remote Sensing and Digital Earth(RADI), Chinese Academy of Sciences Olympic Village Science Park,W. Beichen Road, Beijing 100101, China; baku@ radi.ac.cn

\section{KEY WORD: MODIS-NDVI, Climate Parameter, Time-series trend analysis, Mann-Kendall} \begin{abstract}
:
This study examines MODIS NDVI satellite imagery time series can be used to determine hotspot of land degradation area in whole Mongolia. The trend statistical analysis of Mann-Kendall was applied to a 16-year MODIS NDVI satellite imagery record, based on 16-day composited temporal data (from May to September) for growing seasons and from 2000 to 2016 . We performed to frequency analysis that resulting NDVI residual trend pattern would enable successful determined of negative and positive changes in photo synthetically health vegetation. Our result showed that negative and positive values and generated a map of significant trends. Also, we examined long-term of meteorological parameters for the same period. The result showed positive and negative NDVI trends concurred with land cover types change representing an improve or a degrade in vegetation, respectively. Also, integrated the climate parameters which were precipitation and air temperature changes in the same time period seem to have had an affecting on huge NDVI trend area. The time series trend analysis approach applied successfully determined hotspot of an improvement and a degraded area due to land degradation and desertification.
\end{abstract}

\section{INTRODUCTION}

Desertification is one of the most serious environmental challenges which after affecting the most basic livelihood conditions and resources of people around the world. According to the United Nations highlighted to the first international conference on desertification in Nairobi, Kenya in 1977 (UN Secretariat 1977), land degradation in arid, semi-arid, and dry sub-humid areas further indicated to dry lands might result from various factors, including climatic variations and human activities (UNCCD, 1994; UNCCD 2012). Also, researchers found that the land degradation is a most important issue of societal in order to it is impacts on human populations and environment quality (Vitousek et al. 1997). Moreover, the land degradation is frequently referred to as desertification might be the most important environmental issue. Several researchers were mainly described to that point (Darkoh, 1998; Dregne, 1996; Reynolds, 2001). Specially, Batjargal (1997) recommended that about 35-50 tons of soil have been lost from hectare of cultivated land due to wind erosion alone in over the past 30 years.

Additionally, the study is clear to note that the carrying capacity of pasture land is profound frequently exceeded in the areas receiving he greatest grazing pressure in order to that impact to the degradation for the composition of plant species and soil denudation (Batjargal, 1997). Consequently, an adverse effect of anthropogenic activities such as overgrazing have accelerated, causing vegetation degradation to so that it become the dominant type of rangeland degradation in semi and semi-arid zone. A few studies have been demonstrated that issues (Adyasuren 1998; Batjargal 1999; Fujita et al. 2009).

In additional, some case studies, more strongly highlighted which the rangeland management and monitoring using field surveys, particularly over vast and remote huge areas, may be problematic since these are expensive, manpower-demanding, application and time-consuming processes. Therefore, space platform remote sensing, with it could be cover by large surface area and time frequent, routine observation has been used for broad relate to vegetation applications in environmental monitoring in semi-arid region. For instance, such aspects include: biomass estimation (Jin et al. 2014); NDVI trends from AVHRR and vegetation SPOT (Yin et al. 2012); vegetation indices for the identification of Archaeological Crop marks (Agapiou et al. 2012); Long term vegetation dynamic and response to climatic change (Bao et al. 2014); spatial and temporal variability of vegetation cover (Vandandorj et al. 2015); comparative evaluation of the vegetation dryness index, the temperature vegetation dryness index and the improved for the detect water stress in the semiarid regions (Rahimzadeh et al. 2012); the spatial occurrences of droughts, detected by remotely sensed drought-indices over the desert-steppe and desert geo-botanical zones (Bayarjargal et al. 2006); regional higher resolution based drought monitoring (Ghaleb et al. 2014); Remote sensing of Agro-droughts (Gao et al. 2008); satellite based analysis of recent trends in the ecohydrology of semi-arid region (Gokmen et al. 2013). And another main effect of land degradation is conducted drought process that might be influence and devastate large regions, reduce livestock production, cause economic damage, accelerate desertification in association with destructive human activities. Therefore, in order to it has applied remote sensing-based indices such including normalized difference water index (NDWI), vegetation health index (VHI), temperature condition index (TCI), vegetation condition index (VCI) and meteorological index (PED) in whole territory of Mongolia (Chang et al. 2017). However, as mentioned possibility indices were could not have identified specific narrow area.

There have been several studies representing a generally sufficient agreement on different sensors between the normalized difference vegetation index (NDVI) long term data from 
AVHRR, Spot and MODIS. The grazing and land degradation changes of over Mongolia, based on statistically analysis according to (Erdenetuya, 2004; Eckert et al. 2015). Moreover, some researchers investigated to identifying the most stable and unstable regions of vegetation cover and temporal dynamics compare with precipitation in Mongolia. Some scholars found that highest coefficient of variation $\mathrm{CV}$ vegetation cover occurred frequently in the steppe and desert steppe about high CV more than $30 \%$ has increased in mid-summer season. (Vandandorj et al. 2015). However, could have not studied pressure of animal husbandry to the land degradation.

In this study, the authors are mapping to hotspot area of land degradation in over Mongolia. It has been applied the frequency analysis and Mann-Kendal statistical methods. In addition, an advantage of the study was taken issues of the social economy, climate variables were compared with and remote sensing imagery in order to estimate the land degradation. Moreover, the purpose of an evaluation to the trend of land degradation and identifying hotspot distribution based on geospatial statistic techniques.

\section{STUDY AREA}

The study area's land cover types are high mountain taiga, forest, steppe, desert, semi desert, barren land and others types in Mongolia (Khudulmur et al., 2014). Mongolia is located in the central part of Asia which latitude between $\left(41^{\circ}\right.$ and $52^{\circ} \mathrm{N}$ and longitude between $87^{\circ}$ and $120^{\circ} \mathrm{E}$ ). and a total territory is $1,564,116 \mathrm{~km}^{2}$. About $7 \%$ of the total area covers with forest and $73 \%$ of it dominates by grassland (CIA, 2017).

In contrast, the northern part of area is covered by higher mountains with forested and middle part is a huge grazing land which is steppe area, whereas the southern part covered by the Gobi and desert and semi desert zone with lower elevation and drier climate (Batima et al., 2000). Furthermore, Mongolia has a continental climate and it is characterized by cold, dry and harsh (snowy) winter and warm, limited rainy in summer.

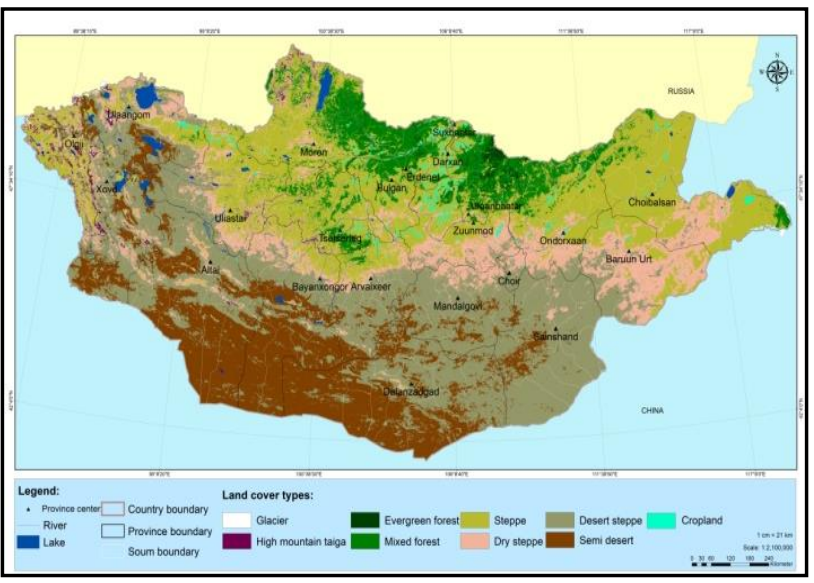

Figure 1. Land cover map of Mongolia and that contains major land cover types such including high mountain, steppe and desert area derived from MODIS/Aqua 250m image.

Some researcher founded that the temperatures range were from approximately $-18^{\circ} \mathrm{C}$ in winter to around $16^{\circ} \mathrm{C}$ in summer (Dagvadorj et al. 1996). Moreover, the amount of annual precipitation is relatively low and it ranges $150-250 \mathrm{~mm}$ in the steppe regions, more than $400 \mathrm{~mm}$ in the mountain areas. Therefore, several researchers were highlighted that $85-90 \%$ of the annual precipitation could have happened in the summer season (Dorjsuren et al., 2016).

\section{MATERIALS AND METHODS}

\subsection{Satellite data}

The normalized difference vegetation index (NDVI) is could use a proxy for terrestrial vegetation efficiency in studies of vegetation trends at regional scales in order to significantly related with ecosystem (Forkel et al. 2013). Terra/MODIS NDVI 250-meter spatial resolution and 16-days composite imagery acquired in from the early of 2000 to $2016^{\prime}$ totally 17 years data. It contains the enhanced vegetation index (EVI) and the normalized difference vegetation index (NDVI) and it has contained the most reliable pixel values (Huete et al. 1999). These some of data from 2000-2008 years were download from the NASA's Earth Observing System Data and Information System (EOSDIS) open source site https://search.earthdata.nasa.gov and another part of data from 2009-2017 years were obtained from Data Catalog Services of the National Remote Sensing Center of Mongolia (NRSC) site www.icc.mn. We collected 11 Julian days are including such as $129,145,161,177,193,209,225,241,257,273$, and 289 that all cover the vegetation phenology stage from May to October.

\subsection{Meteorological and Livestock data}

The meteorological data in Mongolia are situated at 70 the international weather stations in meteorological observation network of World Meteorological Organization some research highlighted that information (Eckert et al. 2015). Currently there are working 130 regional meteorological stations, 186 meteorological posts and 3 upper-air stations in observation network under the National Agency for Meteorology, Hydrology and Environment Monitoring of Mongolia (NAMHEM) Therefore, stabile several parameter were observed variables in all meteorological stations such as includes (Air temperature, surface soil temperature, atmospheric pressure, humidity, velocity and direction of wind, precipitation /amount and intensity/, cloud amount and type, visibility, weather/present and past/, snow depth and density (Battur, 2010) In addition, we were used the precipitation and air temperature of 113 meteorological station data from 2000 to 2016 obtained from the division of database and archive of NAMHEM. The number of livestock data derived from Mongolia Statistical Information Service, site (www.1212.mn) by totally 17 years data collected which between from 2000 to 2016.

\subsection{Method}

In this study, we were used that the one of statistical techniques implemented in the statistical analysis which is the nonparametric Mann-Kendall test for trend (Mann, 1945; Kendall, 1975). Moreover, some researchers noted that the Mann-Kendall test could be viewed as a nonparametric test has considered zero slope value of the linear regression of time-ordered data versus time, according to as highlighted by Hollander and Wolf (1973, p.201). Also, another researcher founded that the yearly aggregation of time series for trend analysis reduced by the temporal resolution and time series length. Therefore, the time series scale is analytical in identifying the significance of the trend in the non-parametrical statistical test (Forkel et al. 2013; Huang et al. 2016).

The land degradation map produced by the Image processing and Geographic information system. All data pre-processing and analysis were used by ERDAS imagine, TerrSET IDRISI the and ArcMAP. So that we aimed to identifying the Hotspot of land degradation over Mongolia by improved, degraded and nonchanged area. In generally, we used biophysics and social economical parameters. Figure 2 represents a workflow of preprocessing and draw map of this study area. 


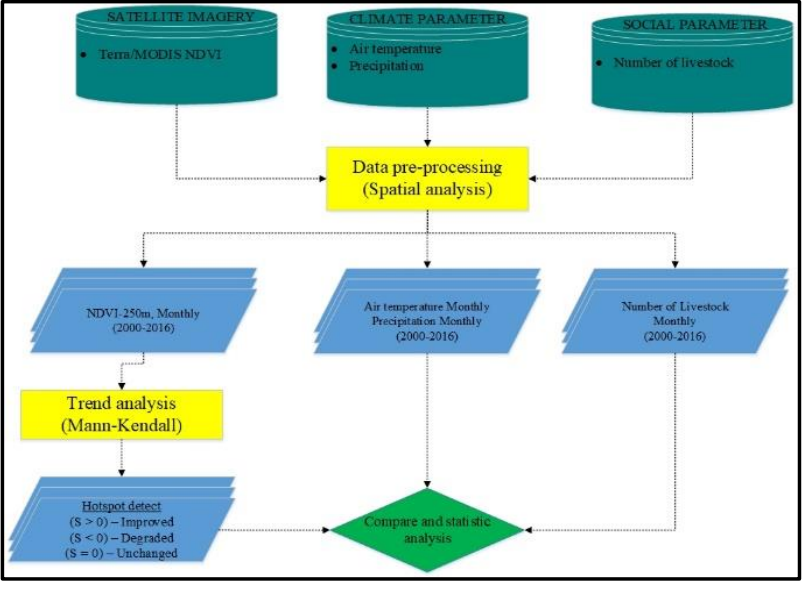

Figure 2. Flowchart of hotspot of land degradation for study area

In workflow processing method, main three different groups were used into several parameters includes such as Terra/MODIS Imagery, Air temperature, Precipitation and number of Livestock etc.

In addition, the spatial analysis was used the image preprocessing and ancillary data analysis. Therefore, pre-processing is used image composite which from per 16 days NDVI to per monthly NDVI, daily meteorological station data convert to monthly data and annual number of livestock. Whereas, the statistical analysis performed the trend and frequency method.

Thus, we have been implemented using the normalized difference vegetation index (NDVI) (Tucker 1979). NDVI is calculated by following Equation (1).

$$
N D V I=\frac{\rho_{N I R}-\rho_{R}}{\rho_{N I R}+\rho_{R}}
$$

Where, $\rho$ are reflectance values in the particular spectral channels. NDVI is built on the difference between the maximum absorption of radiation in the red $(\mathrm{R})$ spectral range (as a result of chlorophyll pigments) and the largest reflection of radiation wave in the near infrared (NIR) range (as a result of leaf cellular texture). The calculation of frequency analysis is computed by following Equation (2).

$$
S=\sum_{k=1}^{n-1} \sum_{j=k+1}^{n} \operatorname{sgn}\left(x_{j}-x_{k}\right)
$$

$$
\operatorname{sgn}\left(x_{j}-x_{k}\right)=\left\{\begin{array}{l}
1 \text { if } x_{j}-x_{k}>0 \\
0 \text { if } x_{j}-x_{k}=0 \\
-1 \text { if } x_{j}-x_{k}<0
\end{array}\right.
$$

Where, $x_{1}, x_{2}, \ldots x_{n}$ is represent $\mathrm{n}$ data points

$$
x_{j} \text { is represent the data point }
$$

$j$ is at time

$S$ is the Mann-Kendall statistic

This the test statistic, $\mathrm{S}$ is equal to the total number of positive differences minus the number of negative differences for each time step.

In order to compare between NDVI changes, air temperature, precipitation and number of livestock the correlation coefficient $(r)$ is calculated the following Equation (3):

$$
r_{x y}=\sum_{i=1}^{n}\left[\left(x_{i}-\bar{x}\right)\left(y_{i}-\bar{y}\right)\right] / \sqrt{\sum_{i=1}^{n}\left[\left(x_{i}-\bar{x}\right)^{2}\left(y_{i}-\bar{y}\right)^{2}\right]}
$$

where, $\quad r_{x y}$ is the correlation coefficient.

$x_{i}$ and $y_{i}$ are the variables of NDVI changes, air temperature, precipitation and number of livestock.

$\bar{x}$ and $\bar{y}$ are the mean value of the variables of NDVI changes, air temperature, precipitation and number of livestock.

$n$ is the number of variables in two parameters.

In addition, the linear correlation $(r)$ in degraded NDVI and number of livestock was explored at annual value, as well as statistical highly significance level $(p)$ have chosen at the $(<0.001)$ in this study.

\section{RESULTS AND DISCUSSION}

The global studies have suggested that the world's semi-arid have been showing a rapidly increase in vegetation activity, the human pressure and as a consequence of warm climate process might impact to land degradation operation (Vicente et al. 2015). Figure 3 shows that the statistical trend of the hotspot of degraded land and Improved land area were demonstrated over in Mongolia from 2000 to 2016 .

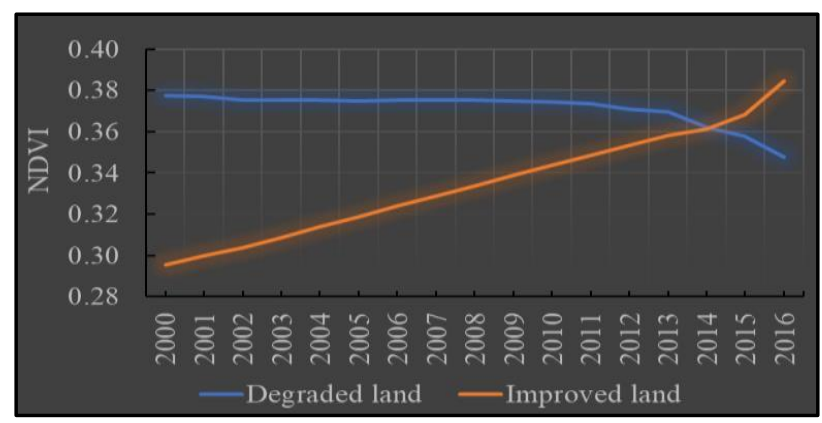

Figure 3. The statistical trend of the hotspot of degraded land and improved land area in study site, 2000-2016

In Figure 3, a trend of trend of the hotspot of degraded land and improved land area have been showing differently phenomena in this study area. In 2000-2010 the degraded land was gradually decreased by from an about 0.380 value to 0.371 value of NDVI, and after that this curve exponentially climbed to an approximate 0.348 of value of NDVI in 2016. On the other hand, the improved land area was dramatically increased from 2000 to 2016 in the study area. Figure 4 represents the relationship between a number of livestock and hotspot of degraded land.

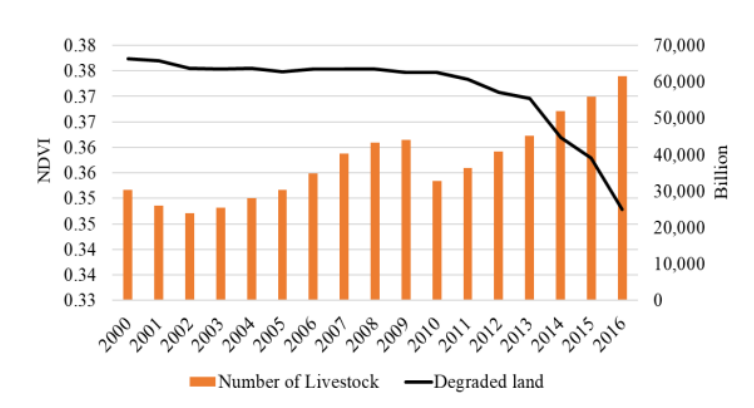

Figure 4. The relationship between the number of livestock and hotspot of degraded land, 2000-2016 
Particularly, the attitude of the number of livestock was gradually grew from 2000 to 2009 , whereas 6 years of number of livestock sharply increased by around 61 billons. In generally, these parameters between livestock and degraded land were well related with each other in the whole study period. The correlation coefficient (r) of the number of livestock and hotspot of degraded land were negative 0.97 with a highly significance level of $p=$ $<0.001$. For example, main assumption was the number of livestock might have pressured to land degradation. Also, another main a comparison analysis of the degraded land, Air temperature and precipitation are illustrated in Figure 5a, b. So that we were compare between the degraded land and climate parameter by each one, a value of warm season combined from May to September for the year 2000 to 2016 in both parameters.

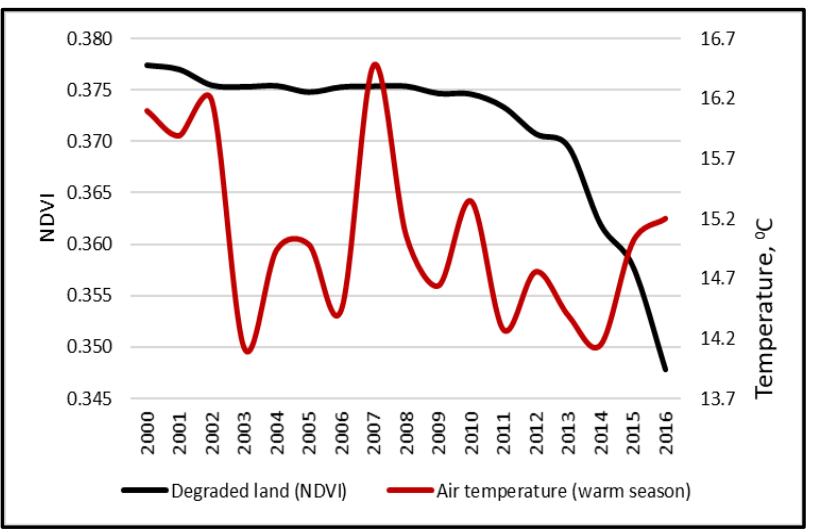

Figure 5a. The temporal variation between degraded land and air temperature.

In figure 5a, the graphic illustrated that air temperature staidly decreased, however 2000, 2001, 2007 and 2016 in highlighted period extremely hot, end of period slightly increasing by about 15.2 Celsius. On the other hand, the degraded land was exponentially decreased.

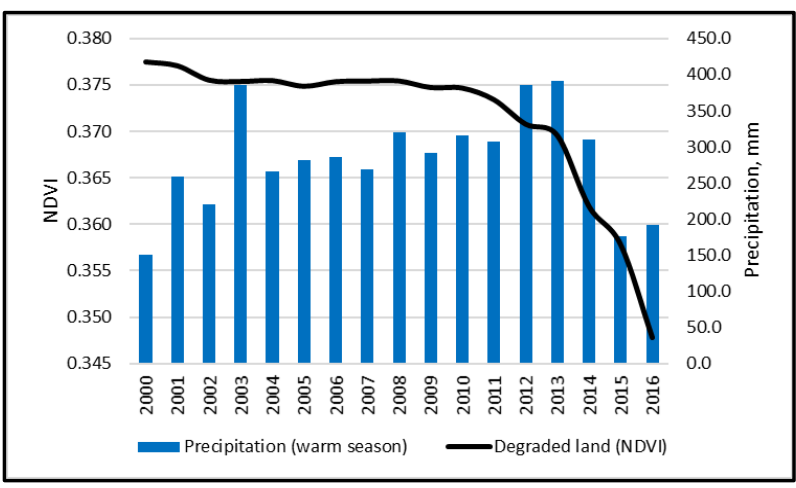

Figure 5b. The temporal variation between degraded land and precipitation.

In figure $5 b$, the graphic showed that the precipitation staidly increased up to in 2013 and rapidly decreased about $200 \mathrm{~mm}$ of annual rainfalls in 2016. For example, some researchers founded that in 2000, 2001, 2007, 2009 were the dries years which is suggesting lower rainfall and higher temperature, in order to became drought occurred in the time 2001 and 2007 (Munkhzul et al. 2016). Therefore, these were as well as related between precipitation and degraded land, particularly last 3 years in this study area.

The final result maps have been representing in figure 6 which is the hotspot area by three categories includes such as degraded area, improved area and unchanged area over period in 17 years.

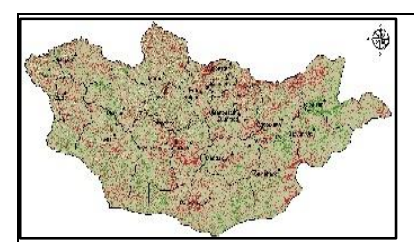

(a.) May

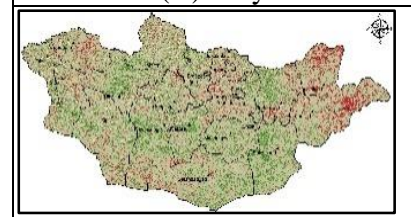

(6c). July

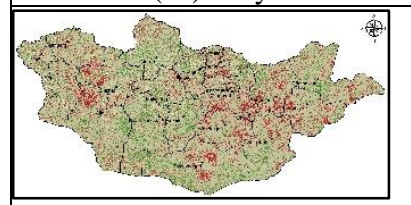

(e.) September

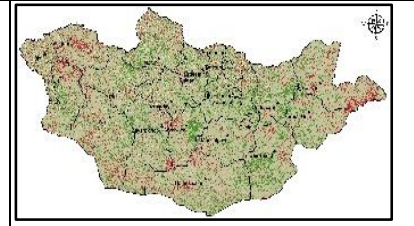

(b.) June

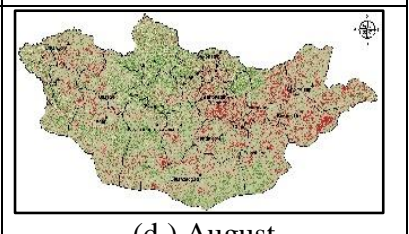

(d.) August
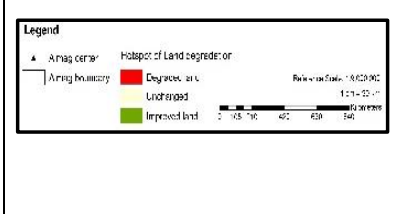

Figure 6. The hotspot of degraded land area of Mongolia

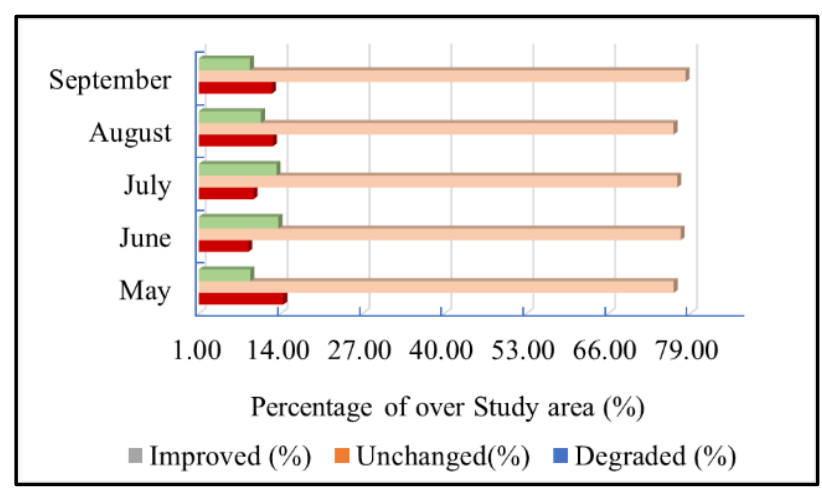

Figure 7. The percentage of hotspot area in over Mongolia from 2000 to 2016 by monthly growing season.

In figure 7, it is interesting to note that even among different kind of the hotspot area normally considered alike such as a degraded area and improved area. But our focus is considered degraded area in order to highly reflect months were May, August and September which are demonstrating in figure $6 \mathrm{a}, 6 \mathrm{~d}$ and $6 \mathrm{e}$, by an approximate $14 \%$ of area. It is situated mainly western, middle, south and eastern half of area are degraded in over period. Moreover, in figure $6 \mathrm{~b}$ and $6 \mathrm{c}$ were about $13 \%$ of area degraded.

Therefore, it is demonstrated by June and July which situated in eastern border to Dornod aimag, and over time within 17 years. On the other hand, improved area was around $12-13 \%$ of study area, and the unchanged area was quite different pattern but not much changed about nearly $79 \%$ in per months, and within 17 years.

\section{CONCLUSION}

This study performs that our proposed approach was used to integrate with the hotspot of land degradation area and social economy both the temporal variation of parameters which analyzed with the number of livestock, air temperature and precipitation by during 17 years from 2000 to 2016 .

We were used that the one of statistical techniques implemented in the statistical analysis which is the nonparametric MannKendall test. The hotspot of land degradation map of study area was classified into three categories and is based on frequency 
trend statistics adequately to assess a respective class: degraded area, unchanged area and improved area. An approximately (14 $\%)$ of the study area was degraded, and about (13\%) of the area improved and around (78\%) of area was unchanged in study area over 17 years.

\section{ACKNOWLEDGEMENTS}

The researchers would like to thank the Earth Observing System Data and Information System (EOSDIS) is a key core capability in NASA's Earth Science Data Systems (ESDS) Program of United States of America (USA), eOsphere Limited (VxEos) of United Kingdom and National Remote Sensing Center (NRSC) of Mongolia for providing raw data and research work.

\section{REFERENCES}

Adyasuren, Ts. 1998. "State of Drought and Desertification in Mongolia.” In Environment and

Agapiou, A., Hadjimitsis, D. G., \& Alexakis, D. D. (2012). Evaluation of broadband and narrowband vegetation indices for the identification of archaeological crop marks. Remote sensing, 4(12), 3892-3919.

Along a Slope with Soil Moisture Gradient.” Grassland Science 55: 126-134.

Bao, G., Qin, Z., Bao, Y., Zhou, Y., Li, W., \& Sanjjav, A. (2014). NDVI-based long-term vegetation dynamics and its response to climatic change in the Mongolian Plateau. Remote Sensing, 6(9), 8337-8358.

Batima, P.; Dagvadorj, D. (2000). Climate Change and Its Impacts in Mongolia; NAMHEM JEMR Publishing: Ulaanbaatar, Mongolia,

Batjargal, Z. (1997). Desertification in Mongolia. RALA report, 200, 107-113.

Batjargal, Z. 1999. "Desertification in Mongolia." In Icelandic Agricultural Research Service

Battur, N. (2010). Observation network of Mongolia. In Proceedings of the JMA/WMO Workshop on Quality Management in Surface, Climate and Upper-Air Observations in RA II (Asia), Tokyo, Japan.

Bayarjargal, Y., Karnieli, A., Bayasgalan, M., Khudulmur, S., Gandush, C., \& Tucker, C. J. (2006). A comparative study of NOAA-AVHRR derived drought indices using change vector analysis. Remote Sensing of Environment, 105(1), 9-22.

Chang, S., Wu, B., Yan, N., Davdai, B., \& Nasanbat, E. (2017). Suitability Assessment of Satellite-Derived Drought Indices for Mongolian Grassland. Remote Sensing, 9(7), 650.

CIA. World Factbook of the Work of a Nation, Central Intelligence Agency: https://www.cia.gov (12 February 2018)

Dagvadorj, D., \& Mijiddorj, R. (1996). Climate change issues in Mongolia. Hydrometeorological Issues in Mongolia: Papers in Hydrometeorology, 79-88.

Darkoh, M. B. K. (1998). The nature, causes and consequences of desertification in the drylands of Africa. Land Degradation \& Development, 9(1), 1-20.
Development Issues in Mongolia, edited by B. Darin, 96 p. Ulaanbaatar: American Center for

Dorjsuren, M., Liou, Y. A., \& Cheng, C. H. (2016). Time series MODIS and in situ data analysis for Mongolia drought. Remote Sensing, 8(6), 509.

Dregne, H. E. (1996). Desertification: challenges ahead. Ann. Arid Zone, 35, 305-311.

Eckert, S., Hüsler, F., Liniger, H., \& Hodel, E. (2015). Trend analysis of MODIS NDVI time series for detecting land degradation and regeneration in Mongolia. Journal of Arid Environments, 113, 16-28.

Erdenetuya, M. (2004). Pasture productivity changes in Mongolia. Geospatial World Application Papers.

Forkel, M., Carvalhais, N., Verbesselt, J., Mahecha, M. D., Neigh, C. S., \& Reichstein, M. (2013). Trend change detection in NDVI time series: Effects of inter-annual variability and methodology. Remote Sensing, 5(5), 2113-2144.

Forkel, M., Carvalhais, N., Verbesselt, J., Mahecha, M. D., Neigh, C. S., \& Reichstein, M. (2013). Trend change detection in NDVI time series: Effects of inter-annual variability and methodology. Remote Sensing, 5(5), 2113-2144.

Fujita, N., N. Amartuvshin, Y. Yamada, K. Matsui, S. Sakai, and N. Yamamura. 2009. "Positive and

Gao, M., Qin, Z., Zhang, H. O., Lu, L., Zhou, X., \& Yang, X. (2008). Remote sensing of agro-droughts in Guangdong Province of China using MODIS satellite data. Sensors, 8(8), 4687-4708.

Ghaleb, F., Mario, M., \& Sandra, A. N. (2015). Regional landsatbased drought monitoring from 1982 to 2014. Climate, 3(3), 563577.

Gokmen, M., Vekerdy, Z., Verhoef, W., \& Batelaan, O. (2013). Satellite-based analysis of recent trends in the ecohydrology of a semi-arid region. Hydrology and earth system sciences, 17(10), 3779 .

Huang, S., \& Kong, J. (2016). Assessing land degradation dynamics and distinguishing human-induced changes from climate factors in the Three-North Shelter forest region of China. ISPRS International Journal of Geo-Information, 5(9), 158.

Jin, Y., Yang, X., Qiu, J., Li, J., Gao, T., Wu, Q., ... \& Xu, B. (2014). Remote sensing-based biomass estimation and its spatiotemporal variations in temperate grassland, Northern China. Remote Sensing, 6(2), 1496-1513.

Kendall, M. G., Rank Correlation Methods, 4th ed., Charles Griffin: London, 1975.

Mann, H. B., Non-parametric test against trend, Econometrica, 13, 245-259, 1945.

Negative Effects of Livestock Grazing on Plant Diversity of Mongolian Nomadic Pasturelands Rahimzadeh-Bajgiran, P., Omasa, K., \& Shimizu, Y. (2012). Comparative evaluation of the Vegetation Dryness Index (VDI), the Temperature Vegetation Dryness Index (TVDI) and the improved TVDI (iTVDI) for water stress detection in semi-arid regions of Iran. ISPRS Journal of Photogrammetry and Remote Sensing, 68, 1-12. 
Reynolds, James F. "Desertification." (2000): 61-78.

RALA, 107-113. Report no. 200. Reykjavik, Iceland.

Vandandorj, S., Gantsetseg, B., \& Boldgiv, B. (2015). Spatial and temporal variability in vegetation cover of Mongolia and its implications. Journal of Arid Land, 7(4), 450-461.

Vandandorj, S., Gantsetseg, B., \& Boldgiv, B. (2015). Spatial and temporal variability in vegetation cover of Mongolia and its implications. Journal of Arid Land, 7(4), 450-461.

Vicente-Serrano, S. M., Cabello, D., Tomás-Burguera, M., Martín-Hernández, N., Beguería, S., Azorin-Molina, C., \& Kenawy, A. E. (2015). Drought variability and land degradation in semiarid regions: Assessment using remote sensing data and drought indices (1982-2011). Remote Sensing, 7(4), 4391-4423.

Vitousek, P. M., Mooney, H. A., Lubchenco, J., \& Melillo, J. M. (1997). Human domination of Earth's ecosystems. Science, 277(5325), 494-499.

Yin, H., Udelhoven, T., Fensholt, R., Pflugmacher, D., \& Hostert, P. (2012). How normalized difference vegetation index (ndvi) trendsfrom advanced very high-resolution radiometer (AVHRR) and système probatoire d'observation de la terre vegetation (spot vgt) time series differ in agricultural areas: An inner mongolian case study. Remote Sensing, 4(11), 3364-3389. 